\title{
Smoking Status and Survival in the National Comprehensive Cancer Network Non-Small Cell Lung Cancer Cohort
}

\author{
Amy K. Ferketich, $\mathrm{PhD}^{1}$; Joyce C. Niland, $\mathrm{PhD}^{2}$; Rizvan Mamet, $\mathrm{MS}^{2}$; Carrie Zornosa, $\mathrm{MSPH}^{3}$; \\ Thomas A. D’Amico, MD4; David S. Ettinger, MD ${ }^{5}$; Gregory P. Kalemkerian, MD ${ }^{6}$; Katherine M. Pisters, MD; \\ Mary E. Reid, $\mathrm{PhD}^{8}$; and Gregory A. Otterson, $\mathrm{MD}^{9}$
}

\begin{abstract}
BACKGROUND: The objectives of this study were to evaluate survival among current smokers, former smokers, and never smokers who are diagnosed with non-small cell lung cancer (NSCLC). METHODS: The study included patients who participated in the National Comprehensive Cancer Network's NSCLC Database Project. Current, former, and never smokers were compared with respect to overall survival by fitting Cox regression models. RESULTS: Data from 4200 patients were examined, including 618 never smokers, 1483 current smokers, 380 former smokers who quit 1 to 12 months before diagnosis, and 1719 former smokers who quit $>12$ months before diagnosis. Among patients with stage I, II, and III disease, only never smokers had better survival than current smokers (hazard ratio, 0.47 [95\% confidence interval, 0.26-0.85] vs 0.51 [95\% confidence interval, 0.38-0.68], respectively). Among patients with stage IV disease, the impact of smoking depended on age: Among younger patients (aged $\leq 55$ years), being a never smoker and a former smoker for $\geq 12$ months increased survival. After age 85 years, smoking status did not have a significant impact on overall survival. CONCLUSIONS: Patients who were smoking at the time of diagnosis had worse survival compared with never smokers. Among younger patients with stage IV disease, current smokers also had worse survival compared with former smokers who quit $>12$ months before diagnosis. It is likely that tumor biology plays a major role in the differences observed; however, to improve survival, it is prudent to encourage all smokers to quit smoking if they are diagnosed with NSCLC. Cancer 2013;119:847-53. (C) 2012 American Cancer Society.
\end{abstract}

KEYWORDS: non-small cell lung cancer, smoking, smoking cessation, survival analysis, prognosis.

\section{INTRODUCTION}

There is a growing body of literature that links smoking with poor outcomes among patients with lung cancer. A recent meta-analysis estimated that individuals who continued to smoke and were diagnosed with early stage non-small cell lung cancer (NSCLC) had 2.94 times the risk of mortality (95\% confidence interval, 1.15-7.54) compared with those who quit at diagnosis. ${ }^{1}$ The meta-analysis results also suggested that smokers with small cell lung cancer are at increased risk of mortality if they continue to smoke. It has been observed that smoking after a diagnosis of lung cancer decreases performance status, ${ }^{2}$ increases the risk of a second primary tumor, ${ }^{3-5}$ and increases the risk of complications from radiation therapy. ${ }^{6}$

Quitting smoking before lung cancer surgery has been the topic of at least 2 reports. Mason and colleagues examined data from the Society of Thoracic Surgeons General Thoracic Surgery Database and observed that mortality and complications were increased among continued smokers and decreased with increasing time since cessation. ${ }^{7}$ Erhunmwunsee and Onaitis reviewed the literature on smoking and lung cancer surgery outcomes and concluded that smoking increases the likelihood of surgical complication rates and that smoking cessation can improve outcomes. ${ }^{8} \mathrm{~A}$ recent study suggests that smokers who quit between diagnosis and surgery are more likely to return to normal functioning after surgery than smokers who do not quit after diagnosis. ${ }^{9}$

Not all studies have concluded that smoking decreases survival among patients with NSCLC. Meguid and colleagues compared current smokers versus never smokers with respect to mortality in a sample of greater than 4500 patients with NSCLC and observed no difference in survival. ${ }^{10}$ Similarly, Toh and coauthors reported no difference between current smokers and never smokers in their sample of 317 patients from Singapore. ${ }^{11}$

Molecular analyses of lung tumor samples in the last decade have demonstrated that particular molecular "driver mutations" are more common in never-smoking patients who have lung cancer compared with patients who have a heavy

Corresponding author: Amy K. Ferketich, PhD, The Ohio State University College of Public Health, 310 Cunz Hall, 1841 Neil Avenue, Columbus, OH 43210 ; Fax: (614) 688-3533; aferketich@cph.osu.edu

${ }^{1}$ The Ohio State University College of Public Health and the Comprehensive Cancer Center, Columbus, Ohio; ${ }^{2}$ City of Hope Comprehensive Cancer Center, Duarte, California; ${ }^{3}$ National Comprehensive Cancer Network, Fort Washington, Pennsylvania; ${ }^{4}$ Duke Cancer Institute, Durham, North Carolina; ${ }^{5}$ The Sidney Kimmel Comprehensive Cancer Center at Johns Hopkins, Baltimore, Maryland; ${ }^{6}$ University of Michigan Comprehensive Cancer Center, Ann Arbor, Michigan; ${ }^{7}$ The University of Texas M. D. Anderson Cancer Center, Houston, Texas; ${ }^{8}$ Roswell Park Cancer Institute, Buffalo, New York; ${ }^{9}$ The Ohio State University College of Medicine and the Comprehensive Cancer Center, Columbus, Ohio

DOI: 10.1002/cncr.27824, Received: June 22, 2012; Revised: August 18, 2012; Accepted: August 20, 2012, Published online September 28, 2012 in Wiley Online Library (wileyonlinelibrary.com) 
smoking history. ${ }^{12,13}$ Defining these molecularly characterized subtypes is incredibly important in the choice of therapeutic options for patients with advanced or metastatic disease, although there is less evidence to date that choice of therapy should be altered according to molecular classification for patients with earlier stage disease (stages I-III). The impact of these molecular differences on prognosis, however, is somewhat more mixed. For example, although patients who have epidermal growth factor receptor $(E G F R)$ mutations (an estimated $40 \%-60 \%$ of never smokers with lung cancer) may have a better prognosis than patients without EGFR mutations, ${ }^{14}$ it has recently been suggested that patients who have anaplastic lymphoma kinase $(A L K)$ translocations (which also are observed more frequently in never smokers) do not bear an improved prognosis (absent treatment with the appropriate tyrosine kinase inhibitor). ${ }^{15}$

The National Comprehensive Cancer Network (NCCN) is a multisite network with 21 cancer centers covering nearly every region of the United States. The NCCN NSCLC Database Project, which was established in 2008, contains clinical and treatment information on eligible patients with NSCLC from 8 NCCN sites. We used data from the NCCN NSCLC Database Project to compare survival among current, former, and never smokers who were diagnosed with NSCLC.

\section{MATERIALS AND METHODS}

\section{Participants}

The study cohort consisted of patients who presented to 1 of the $8 \mathrm{NCCN}$ member institutions participating in the NSCLC Database Project through December 2011. The NCCN sites include the following cancer centers: City of Hope, Duarte, Calif; Duke Cancer Institute, Durham, NC; The Sidney Kimmel Comprehensive Cancer Center at Johns Hopkins, Baltimore, Md; The University of Michigan Comprehensive Cancer Center, Ann Arbor, Mich; The University of Texas M. D. Anderson Cancer Center, Houston, Tex; Roswell Park Cancer Institute, Buffalo, NY; and The Ohio State University Comprehensive Cancer Center-James Cancer Hospital and Solove Research Institute, Columbus, Ohio. Patients with a recent diagnosis of NSCLC (within the past 6 months) are included in the database. Patients were excluded from the analysis if they had 1 or more of the following: 1) presented with a nonrecent NSCLC diagnosis (>180 days ago); 2) had incomplete baseline data, including demographic, medical history, or smoking status data; 3) had incomplete staging; 4) had a past diagnosis of cancer; or 5) had $<180$ days of follow-up, unless they died within 180 days.

\section{Measures}

All data were collected from medical record review and abstraction. A database manager/cancer registrar from each participating site abstracted data from patient records and entered these data into a deidentified central database maintained at the data Coordinating Center located at City of Hope in Duarte, Calif.

The primary independent variable was smoking status at diagnosis. The 4 categories that were used for this analysis were: 1) never smoker, 2) former smoker for 1 to 12 months before diagnosis, 3) former smoker for $>12$ months before diagnosis, and 4) current smoker. Smokers who had $\leq 10$ pack-years of smoking were excluded from the former and current smoker groups because of their small sample size $(\mathrm{n}=250)$ in the cohort. Other variables of interest were stage of disease (stage I and II combined, stage III, or stage IV), histology (squamous cell, adenocarcinoma and bronchioloalveolar [BAC], or other), age at diagnosis, sex, race (white or other), Charlson comorbidity $\operatorname{score}^{16}(0 \mathrm{vs} \geq 1)$, receipt of drug therapy (chemotherapy and targeted therapy), receipt of radiation therapy, receipt of surgery, performance status, and NCCN institution. Patients with stage I and II disease were combined into 1 group, because these stages represent localized disease that are treated primarily with surgical resection, with our without adjuvant chemotherapy. In addition, the number of patients with stage II disease was small, which would have made comparisons by smoking status within the group of stage II patients difficult.

The outcome of interest was death from any cause during the follow-up period. Follow-up for survival analysis was defined as the time in years from tumor diagnosis to the date of death from any cause or last known vital status date.

\section{Statistical Analysis}

Descriptive statistics, including the mean and standard deviation for continuous variables and frequency distributions for categorical variables, were calculated according to smoking status category. Two-year survival and Kaplan-Meier survival curves were estimated for each smoking group. Stage-specific Cox proportional hazards models were used to examine the association between survival and smoking status after testing the proportionality assumption and adjusting for potential significant confounders. Hazard ratios (HRs) and 95\% confidence intervals (CI) were estimated for each smoking group using current smokers as the reference group. In addition, sensitivity analyses were performed to determine whether the minimum 180-day follow-up rule had an impact on the 
results, and these analyses did not reveal any substantial influence of this inclusion criterion.

To build the final adjusted multivariable Cox proportional hazards models, the effect of each of the following 10 potential confounding variables on the survival of different smoking groups was evaluated: age, NCCN institution, sex, race, Charlson comorbidity score, Eastern Cooperative Oncology Group performance status, histology, receipt of drug therapy, receipt of radiation therapy, and receipt of resection. The approach to model building involved adding only variables that altered the coefficients for smoking status by $\geq 20 \%$ rather than adding all variables that significantly predicted survival. Hence, we did not build a "prediction" model, because the objective was to determine the unconfounded association between smoking status and survival. The interaction effects of smoking status with age and with sex also were evaluated in all final multivariable models.

The functional form of age was tested using cumulative martingale residual plots. Because the test revealed a linear relation, age at diagnosis was used as continuous variable in all models. Proportional hazards assumptions were evaluated for each variable in the final models by examining Schoenfeld residuals and by fitting interaction terms of each covariate with time in the final model. Overall goodness-of-fit was established using likelihood ratio tests. All final models met proportional hazards assumptions, achieved good fit, and converged according to likelihood ratio tests. All statistical analyses were performed using the SAS statistical software package (version 9.3; SAS Institute Inc., Cary, NC).

\section{RESULTS}

In total, 6361 newly diagnosed patients were accrued to the database between January 2007 and December 2011. Patients were eliminated from the cohort if they had a past history of cancer diagnosis $(n=700)$, if they had $<180$ days of follow-up $(n=935)$, if they had an incomplete baseline medical history or demographic or staging information $(\mathrm{n}=10)$, if they had no information on former versus current smoking status at diagnosis $(n=65)$, or if they were light smokers who smoked $\leq 10$ pack-years $(n=250)$. The final sample size for the analysis was 4200 patients. This included 618 never smokers (15\%), 1483 current smokers (35\%), 380 former smokers who quit 1 to 12 months before diagnosis (9\%), and 1719 former smokers who quit $>12$ months before diagnosis (41\%).

Table 1 contains the descriptive statistics, overall and by smoking status category. Half of the participants were men, $85 \%$ were white, and the average age was 64 years. With respect to disease stage, $28 \%$ were diagnosed with stage I or II disease, $27 \%$ were diagnosed with stage III disease, and $45 \%$ were diagnosed with stage IV disease. Greater than $50 \%$ of participants were diagnosed with adenocarcinoma (58\%), 25\% were diagnosed with squamous cell carcinoma, and the remaining $17 \%$ were diagnosed with another histologic type. Approximately $50 \%$ of participants had a Charlson comorbidity score of $0(51 \%)$. Close to $66 \%$ of participants had received radiation treatment or drug therapy (64\% and 65\%, respectively), and $34 \%$ underwent surgical resection. These descriptive statistics demonstrate that this cohort is representative of the larger population of patients with NSCLC in the United States.

Survival information is presented in Table 2, and survival plots are presented in Figures 1, 2, and 3. Among patients with stage I and II disease, the median survival has not yet been reached for most smoker groups, and the 2-year survival estimates ranged from $72 \%$ (current smokers) to $93 \%$ (never smokers). Among the patients with stage III disease, the median survival ranged from 20.1 months (current smokers) to 37.3 months (never smokers), and the 2-year survival estimates ranged from $41 \%$ (current smokers) to 66\% (never smokers). Among the patients with stage IV disease, the median survival ranged from 6.7 months (current smokers) to 19.6 months (never smokers), and the 2-year survival estimates ranged from $15 \%$ (current smokers) to $40 \%$ (never smokers).

Results from the Cox proportional hazards models are presented in Table 3, which lists the variables that were included in the model. The variables age and NCCN site were included in all models, radiation treatment and resection status were included in the stage I/II and stage III models, drug therapy and performance status were included in the stage III and stage IV models, and histology was included only in the stage I/II model. Among patients with stage I and II disease, never smokers had a significantly lower hazard for all-cause mortality compared with current smokers (HR, 0.47; 95\% CI, $0.26-0.85)$. The results were not statistically significant for former smokers who quit 1 to 12 months before diagnosis (HR, 0.80; 95\% CI, 0.51-1.24) and former smokers who quit $>12$ months before diagnosis (HR, 0.84; $95 \%$ CI, 0.65-1.08). Among patients with stage III disease, the results were similar: Never smokers had a significantly lower mortality (HR, 0.51; 95\% CI, 0.38-0.68), and former smokers had a nonsignificantly lower mortality (former smokers 1-12 months before diagnosis: HR, 0.79; 95\% CI, 0.59-1.07; former smokers $>12$ months before diagnosis: HR, 0.85; 95\% CI, 0.70-1.03). 
TABLE 1. Baseline Characteristics of Participants in the Non-small Cell Lung Cancer Database Project According to Smoking Status

\begin{tabular}{|c|c|c|c|c|c|}
\hline \multirow[b]{3}{*}{ Characteristic } & \multicolumn{5}{|c|}{ No. of Patients (\%) } \\
\hline & \multirow[b]{2}{*}{$\begin{array}{l}\text { Never Smokers, } \\
n=618\end{array}$} & \multirow[b]{2}{*}{$\begin{array}{l}\text { Current Smokers, } \\
\qquad \mathrm{n}=1483^{\mathrm{a}}\end{array}$} & \multicolumn{2}{|c|}{ Former Smokers $^{a}$} & \multirow[b]{2}{*}{$\begin{array}{c}\text { Total Sample } \\
n=4200\end{array}$} \\
\hline & & & $\begin{array}{c}\text { 1-12 Months, } \\
\mathrm{n}=380\end{array}$ & $\begin{array}{c}\geq 12 \text { Months, } \\
n=1719\end{array}$ & \\
\hline Men & $212(34)$ & $781(53)$ & $189(50)$ & $918(53)$ & $2100(50)$ \\
\hline Caucasians & $472(76)$ & $1248(84)$ & $312(82)$ & $1534(89)$ & $3566(85)$ \\
\hline $\begin{array}{l}\text { Age at Diagnosis: } \\
\text { Mean } \pm \text { SD, y }\end{array}$ & $61.3 \pm 13.1$ & $61.0 \pm 10$ & $62.1 \pm 9.4$ & $68.0 \pm 9.4$ & $64.0 \pm 10.8$ \\
\hline \multicolumn{6}{|l|}{ Disease stage } \\
\hline I and II & $123(20)$ & $406(27)$ & $101(27)$ & $565(33)$ & $1195(28)$ \\
\hline III & $149(24)$ & $401(27)$ & $99(26)$ & $468(27)$ & $1117(27)$ \\
\hline IV & $346(56)$ & $676(46)$ & $180(47)$ & $686(40)$ & $1888(45)$ \\
\hline \multicolumn{6}{|l|}{ Histology } \\
\hline Squamous cell & $40(6)$ & $431(29)$ & $105(28)$ & $471(27)$ & $1047(25)$ \\
\hline \multicolumn{6}{|l|}{ Adenocarcinoma } \\
\hline NOS and BAC & $504(82)$ & $756(51)$ & $193(51)$ & $967(56)$ & $2420(58)$ \\
\hline Other & $74(12)$ & $296(20)$ & $82(22)$ & $281(16)$ & $733(17)$ \\
\hline \multicolumn{6}{|c|}{ Charlson Comorbidity score } \\
\hline 0 & $482(78)$ & $686(46)$ & $195(51)$ & $763(44)$ & $2126(51)$ \\
\hline$\geq 1$ & $136(23)$ & $797(54)$ & $185(49)$ & $956(56)$ & 2074 (49) \\
\hline \multicolumn{6}{|l|}{ Drug therapy } \\
\hline Yes & $422(68)$ & 987 (67) & 239 (63) & 1089 (63) & 2737 (65) \\
\hline No & 259 (42) & $436(29)$ & $123(32)$ & 679 (39) & $1463(35)$ \\
\hline \multicolumn{6}{|l|}{ Resective surgery } \\
\hline Yes & $182(29)$ & 479 (32) & $132(35)$ & $614(36)$ & 1407 (34) \\
\hline No & $436(71)$ & $1004(68)$ & $248(65)$ & $1105(64)$ & 2793 (67) \\
\hline
\end{tabular}

Abbreviations: BAC, bronchioloalveolar carcinoma; NOS, not otherwise specified; SD, standard deviation.

${ }^{a}$ This analysis excluded patients who had $\leq 10$ pack-years of smoking.

TABLE 2. Number of Deaths, Censored Observations, Median, and Two-Year Survival According to Smoking Status and Disease Stage

\begin{tabular}{|c|c|c|c|c|c|}
\hline $\begin{array}{l}\text { Smoking Status by } \\
\text { Disease Stage }\end{array}$ & $\begin{array}{l}\text { Total No. } \\
\text { of Patients }\end{array}$ & $\begin{array}{l}\text { No. of } \\
\text { Deaths }\end{array}$ & $\begin{array}{l}\text { No. Censored } \\
(\%)\end{array}$ & $\begin{array}{c}\text { Median } \\
\text { Survival, mo }\end{array}$ & $\begin{array}{c}\text { Two-Year Survival } \\
{[95 \% \mathrm{Cl}], \%}\end{array}$ \\
\hline \multicolumn{6}{|l|}{ Stage $\mathrm{I}$ and $\mathrm{II}, \mathrm{n}=1195$} \\
\hline Current smokers ${ }^{\mathrm{a}}$ & 406 & 116 & $290(71.4)$ & 46.9 & 72.4 [66.9-77] \\
\hline \multicolumn{6}{|l|}{ Former smokers } \\
\hline $1-12 \mathrm{mo}^{\mathrm{a}}$ & 101 & 26 & $75(74.3)$ & $N A^{b}$ & 80 [70-87] \\
\hline$\geq 12 \mathrm{mo}^{\mathrm{a}}$ & 565 & 146 & $419(74.2)$ & $N A^{b}$ & $75.5[71.1-79.3]$ \\
\hline Never smokers & 123 & 13 & $110(89.4)$ & $N A^{b}$ & $93.4[86.6-98.9]$ \\
\hline \multicolumn{6}{|l|}{ Stage III, $\mathrm{n}=1117$} \\
\hline Current smokers ${ }^{a}$ & 401 & 240 & $161(40.2)$ & 20.1 & $40.6[35.3-46]$ \\
\hline \multicolumn{6}{|l|}{ Former smokers } \\
\hline $1-12 \mathrm{mo}^{\mathrm{a}}$ & 99 & 59 & $40(40.4)$ & 20.2 & $45.2[34.4-55.4]$ \\
\hline$\geq 12 \mathrm{mo}^{\mathrm{a}}$ & 468 & 253 & $215(45.9)$ & 22.5 & $49.2[44.2-54]$ \\
\hline Never smokers & 149 & 65 & $84(56.4)$ & 37.3 & $66.4[57.5-73.9]$ \\
\hline \multicolumn{6}{|l|}{ Stage IV, $\mathrm{n}=1888$} \\
\hline Current smokers ${ }^{a}$ & 676 & 570 & $106(15.7)$ & 6.7 & $15.3[12.5-18.4]$ \\
\hline \multicolumn{6}{|l|}{ Former smokers } \\
\hline $1-12 \mathrm{mo}^{\mathrm{a}}$ & 180 & 151 & $29(16.1)$ & 7.2 & 19.6 [13.9-26] \\
\hline$\geq 12 \mathrm{mo}^{\mathrm{a}}$ & 686 & 568 & $118(17.2)$ & 8.5 & $19.7[16.7-23]$ \\
\hline Never smokers & 346 & 219 & $127(36.7)$ & 19.6 & $40.4[34.7-45.9]$ \\
\hline
\end{tabular}

Abbreviations: $\mathrm{Cl}$, confidence interval; NA, not available.

${ }^{a}$ This analysis excluded patients who had $\leq 10$ pack-years of smoking.

${ }^{\mathrm{b}}$ Median survival was not yet reached in patients with stage I and II disease. 


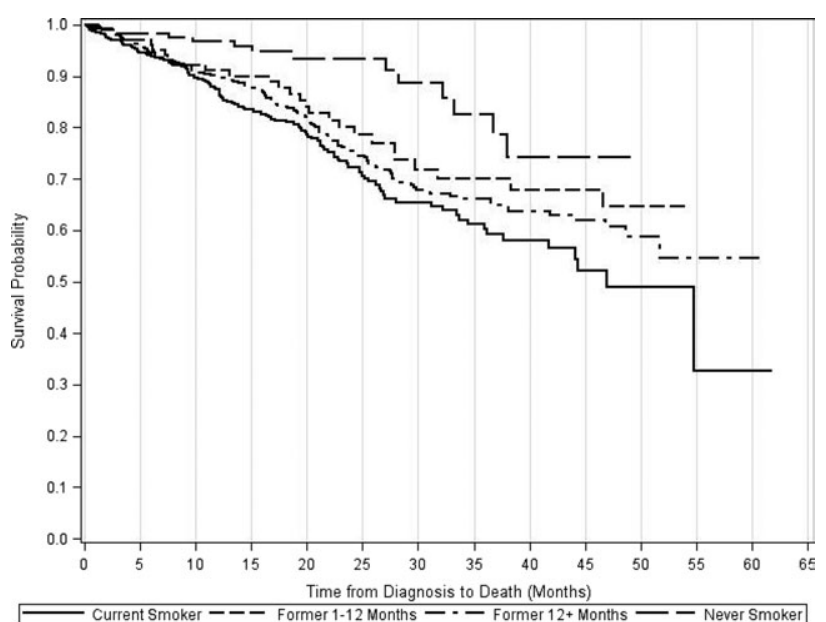

Figure 1. This is a Kaplan-Meier survival plot for patients with stage I and II non-small cell lung cancer according to smoking status at diagnosis

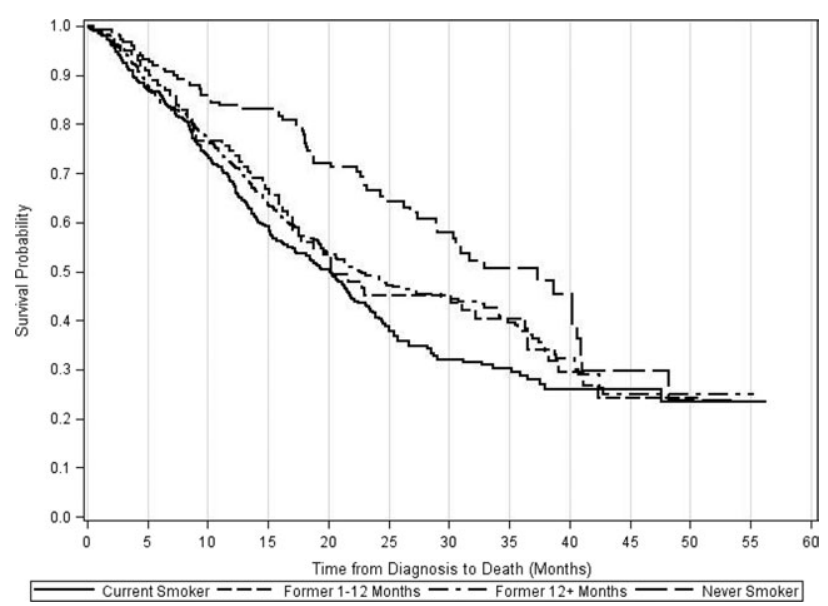

Figure 2. This is a Kaplan-Meier survival plot for patients with stage III non-small cell lung cancer according to smoking status at diagnosis.

Among patients with stage IV disease, there was a significant interaction between smoking status and age $(P=.02)$. Table 3 includes $H R s$ for various ages using the model coefficient estimates to calculate HRs and 95\% CIs. In general, among younger patients, former smokers who quit $>12$ months before diagnosis and never smokers had a significantly lower risk of death compared with current smokers. With increasing age, the benefits of being a former smoker $>12$ months before diagnosis or a never smoker diminished, and former smokers who quit $>12$ months before diagnosis lost the beneficial effect at a faster pace than never smokers. Smoking had no effect on survival among patients aged $\geq 85$ years.

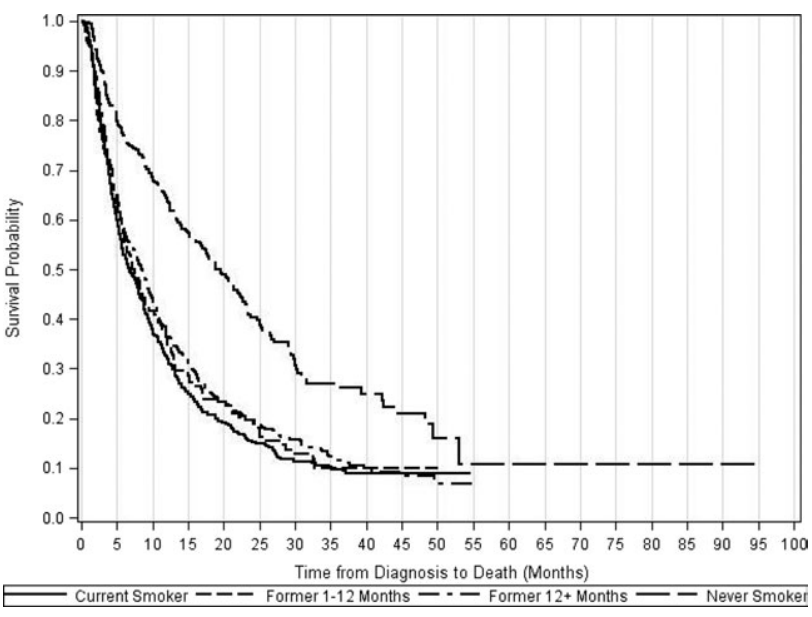

Figure 3. This is a Kaplan-Meier survival plot for patients with stage IV non-small cell lung cancer according to smoking status at diagnosis.

\section{DISCUSSION}

The results from our analysis of patients in the NCCN database, which is 1 of the largest cohorts of patients with NSCLC, suggest that individuals who were smoking at the time of diagnosis had worse survival compared with never smokers. The results for patients with stage IV disease suggest that, among younger individuals, current smokers had worse survival compared with both former smokers who had quit $>12$ months before diagnosis and never smokers; however, as age increased, the benefits of being a former smoker as well as a never smoker decreased.

Previous research suggests that never smokers and smokers who quit smoking more than 1 year in advance of diagnosis have a better survival rate, but most of the significant differences have been observed among patients with early stage NSCLC. In their sample of 543 patients with early stage NSCLC, Zhou and colleagues reported that never smokers had half the risk of dying and that former smokers who quit $\geq 9$ years before diagnosis had a $>30 \%$ reduced risk of dying compared with current smokers. ${ }^{17}$ Nia and colleagues reported a similar reduced risk among never smokers and former smokers in their study of 311 patients who underwent curative resection for NSCLC. ${ }^{18}$ Ebbert and coauthors, in their sample of 4618 patients with NSCLC, observed that only women with NSCLC who were former smokers had a reduced risk of dying compared with current smokers; however, all patients in that study who were never smokers had a lower risk of dying compared with current smokers. ${ }^{19}$ In another study of patients with NSCLC, never smokers had a significant survival advantage over smokers only among those with stage I NSCLC, and never smokers with stage II or III disease 
TABLE 3. Results From Cox Proportional Hazards Regression Models According to Disease Stage

\begin{tabular}{|c|c|}
\hline Variable & $\mathrm{HR}(95 \% \mathrm{Cl})^{\mathrm{a}}$ \\
\hline \multicolumn{2}{|c|}{ Stage $\mathrm{I}$ and II, $\mathrm{n}=1195$} \\
\hline Current smokers & 1.00 \\
\hline \multicolumn{2}{|l|}{ Former smokers } \\
\hline $1-12 \mathrm{mo}$ & $0.80(0.51-1.24)$ \\
\hline$>12 \mathrm{mo}$ & $0.84(0.65-1.08)$ \\
\hline Never smokers & $0.47(0.26-0.85)$ \\
\hline \multicolumn{2}{|l|}{ Stage III, $\mathrm{n}=1117$} \\
\hline Current smokers & 1.00 \\
\hline \multicolumn{2}{|l|}{ Former smokers } \\
\hline $1-12 \mathrm{mo}$ & $0.79(0.59-1.07)$ \\
\hline$>12 \mathrm{mo}$ & $0.85(0.70-1.03)$ \\
\hline Never smokers & $0.51(0.38-0.68)$ \\
\hline \multicolumn{2}{|l|}{ Stage IV, $n=1888$} \\
\hline \multicolumn{2}{|c|}{ Estimates for patients aged $45 \mathrm{y}$} \\
\hline Current smokers & 1.00 \\
\hline \multicolumn{2}{|l|}{ Former smokers } \\
\hline $1-12 \mathrm{mo}$ & $1.09(0.77-1.55)$ \\
\hline$>12 \mathrm{mo}$ & $0.70(0.53-0.91)$ \\
\hline Never smokers & $0.39(0.30-0.51)$ \\
\hline \multicolumn{2}{|c|}{ Estimates for patients aged 55 y } \\
\hline Current smokers & 1.00 \\
\hline \multicolumn{2}{|l|}{ Former smokers } \\
\hline $1-12 \mathrm{mo}$ & $1.02(0.83-1.26)$ \\
\hline$>12 \mathrm{mo}$ & $0.78(0.66-0.93)$ \\
\hline Never smokers & $0.48(0.40-0.57)$ \\
\hline \multicolumn{2}{|c|}{ Estimates for patients aged $65 \mathrm{y}$} \\
\hline Current smokers & 1.00 \\
\hline Never smokers & $0.95(0.77-1.16)$ \\
\hline \multicolumn{2}{|l|}{ Former smokers } \\
\hline $1-12 \mathrm{mo}$ & $0.88(0.77-1.00)$ \\
\hline$>12 \mathrm{mo}$ & $0.58(0.49-0.69)$ \\
\hline \multicolumn{2}{|c|}{ Estimates for patients aged 75 y } \\
\hline Current smokers & 1.00 \\
\hline Never smokers & $0.88(0.63-1.24)$ \\
\hline \multicolumn{2}{|l|}{ Former smokers } \\
\hline $1-12 \mathrm{mo}$ & $0.99(0.81-1.20)$ \\
\hline$>12 \mathrm{mo}$ & $0.70(0.54-0.92)$ \\
\hline \multicolumn{2}{|c|}{ Estimates for patients aged 85 y } \\
\hline Current smokers & 1.00 \\
\hline Never smokers & $0.82(0.49-1.38)$ \\
\hline \multicolumn{2}{|l|}{ Former smokers } \\
\hline $1-12 \mathrm{mo}$ & $1.11(0.82-1.49)$ \\
\hline$>12 \mathrm{mo}$ & $0.86(0.58-1.26)$ \\
\hline
\end{tabular}

Abbreviations: $\mathrm{Cl}$, confidence interval; $\mathrm{HR}$, hazard ratio.

a The stage I and II model was adjusted for National Comprehensive Cancer Network (NCCN) institution, age at diagnosis, histology, resection status, and receipt of radiation; the latter 2 variables were stratified because of nonproportionality. The stage III model was adjusted for NCCN institution, age at diagnosis, receipt of radiation, resection status, receipt of drug therapy, and ECOG performance status; the latter 3 variables were stratified because of nonproportionality. The stage IV model was adjusted for NCCN institution, age at diagnosis, receipt of drug therapy, and Eastern Cooperative Oncology Group performance status; the latter 2 variables were stratified because of nonproportionality.

experienced a nonsignificant reduced risk of dying. ${ }^{20}$ In contrast, Tammemagi and colleagues observed no difference according to disease stage in patients with NSCLC; all never smokers in their study experienced a reduced risk of dying compared with current smokers. ${ }^{21}$ Our findings among patients with early stage NSCLC are consistent with previous studies, in that we observed improved survival among never smokers; however, we also noted that younger never smokers and former smokers with late-stage disease had a survival advantage over current smokers.

Former smokers who quit within 1 year of diagnosis had a nonsignificant reduction in mortality compared with current smokers. Zhou and colleagues reported a similar nonsignificant reduction in the risk of dying among former smokers who quit close to diagnosis. ${ }^{17}$ Other studies have reported significant differences between recent quitters and current smokers with respect to survival among patients with NSCLC. Nia and coauthors concluded that patients with early stage NSCLC who quit between diagnosis and surgery were significantly less likely to die than current smokers. ${ }^{18}$ Because smoking status was assessed only once for patients in the NCCN database project, we were not able to include individuals who quit at diagnosis in our "former smoker for 1 to 12 months" group.

We are unaware of other studies reporting a similar interaction between age and smoking status with regard to the survival of patients with NSCLC. In our current study, this interaction was significant only for patients with stage IV disease. It is possible that, because we had a larger sample size of patients with stage IV disease, we had more power to detect this interaction in this group compared with the other stage groups. Smoking may be a stronger risk factor for death among younger individuals compared with older individuals. There is at least 1 report demonstrating such an interaction on all-cause mortality in the general population in the United States. In a longitudinal study of 4916 American men and women, current smoking was a significant predictor of mortality in the in the groups ages 60 to 69 years and 70 to 79 years, but not in the group aged $\geq 80$ years. ${ }^{22}$

The strengths of this study include the large overall sample size, which allowed us to examine the association between smoking and survival according to disease stage. A second strength of this study is the representative sample of patients in the NCCN database. The clinical sites are located in 8 states throughout the United States. Thus, regional differences in patient characteristics are accounted for in the analysis.

Limitations of this study include those that are common in research that relies on the use of a database. First, smoking status was only measured at diagnosis; thus, we could not evaluate the effect of quitting smoking after diagnosis on survival. Second, detailed information on smoking history was not obtained. A third limitation relates to the sample size for former smokers who quit within 1 year of 
diagnosis. This group comprised relatively few study participants $(\mathrm{n}=380)$; thus, the nonsignificant results observed may be attributed to this smaller sample size. A fourth limitation relates to the finding that we did not have information on socioeconomic status, which is strongly associated with smoking status. Because we relied on medical chart data, it was not possible to consistently collect information on income, occupation, or education, all of which may be used as proxies for socioeconomic status. Finally, although data regarding the molecular characterization of these patients are currently being collected, for most of these patients, the status of $E G F R$ and v-Ki-ras2 Kirsten rat sarcoma viral oncogene homolog $(K$-ras $)$ mutations, echinoderm microtubule associated protein-like 4 (EML4-ALK) translocations, and other changes is not known. The impact of these distinct molecular subtypes of lung cancer is likely to be greatest in patients with recurrent or metastatic disease, in that treatment with molecular-targeted agents against EGFR or ALK (erlotinib and crizotinib, respectively) is not typically done outside of a clinical trial in patients with stage I, II, or III disease.

In conclusion, the results from this analysis of 4200 patients with NSCLC suggest that individuals who were smoking at the time of diagnosis had worse survival compared with never smokers. Among younger patients with stage IV NSCLC, current smokers also had worse survival compared with former smokers who quit $>12$ months before diagnosis. Although some of these differences probably are related to tumor biology, it is prudent to recommend that all smokers, even those with a high pack-year history of smoking, should be encouraged to quit smoking to improve their potential survival if they are diagnosed with NSCLC. Younger patients who were diagnosed with late-stage cancer and who quit smoking $>12$ months before diagnosis experienced a significantly decreased risk of dying, and most smokers who quit within 1 year of diagnosis had a lower, albeit nonsignificant, risk of dying compared with current smokers at the time of diagnosis.

\section{FUNDING SOURCES}

No specific funding was disclosed.

\section{CONFLICT OF INTEREST DISCLOSURES}

The authors made no disclosures.

\section{REFERENCES}

1. Parsons A, Daley A, Begh R, Aveyard P. Influence of smoking cessation after diagnosis of early stage lung cancer on prognosis: systematic review of observational studies with meta-analysis [serial online]. BMJ. 2010;340:b5569.
2. Baser S, Shannon VR, Eapen GA, et al. Smoking cessation after diagnosis of lung cancer is associated with a beneficial effect on performance status. Chest. 2006;130:1784-1790.

3. Kawahara M, Ushijima S, Kamimori T, et al. Second primary tumours in more than 2-year disease-free survivors of small-cell lung cancer in Japan: the role of smoking cessation. $\mathrm{Br} J$ Cancer. 1998;78:409-412.

4. Richardson GE, Tucker MA, Venzon DJ, et al. Smoking cessation after successful treatment of small-cell lung cancer is associated with fewer smoking-related second primary cancers. Ann Intern Med. 1993;119:383-390.

5. Tucker MA, Murray N, Shaw EG, et al. Second primary cancers related to smoking and treatment of small-cell lung cancer. Lung Cancer Working Cadre. J Natl Cancer Inst. 1997;89:17821788 .

6. Rugg T, Saunders MI, Dische S. Smoking and mucosal reactions to radiotherapy. Br J Radiol. 1990;63:554-556.

7. Mason DP, Subramanian S, Nowicki ER, et al. Impact of smoking cessation before resection of lung cancer: a Society of Thoracic Surgeons General Thoracic Surgery Database study. Ann Thorac Surg. 2009;88:362-370.

8. Erhunmwunsee L, Onaitis MW. Smoking cessation and the success of lung cancer surgery. Curr Oncol Rep. 20091;11:269274.

9. Balduyck B, Nia PS, Cogen A, et al. The effect of smoking cessation on quality of life after lung cancer surgery. Eur J Cardiothorac Surg. 2011;40:1432-1437.

10. Meguid RA, Hooker CM, Harris J, et al. Long-term survival outcomes by smoking status in surgical and nonsurgical patients with non-small cell lung cancer: comparing never smokers and current smokers. Chest. 2010;138:500-509.

11. Toh CK, Wong EH, Lim WT, et al. The impact of smoking status on the behavior and survival outcome of patients with advanced non-small cell lung cancer: a retrospective analysis. Chest. 2004;126:1750-1756.

12. Herbst RS, Heymach JV, Lippman SM. Molecular origins of cancer: lung cancer. N Engl J Med. 2008;359:1367-1380.

13. Subramanian J, Govindan R. Molecular genetics of lung cancer in people who have never smoked. Lancet Oncol. 2008;9:676682.

14. Sonobe M, Kobayashi M, Ishikawa M, et al. Impact of KRAS and EGFR gene mutations on recurrence and survival in patients with surgically resected lung adenocarcinomas. Ann Surg Oncol. 2012;19(suppl 3):347-354.

15. Shaw AT, Yeap BY, Solomon BJ, et al. Effect of crizotinib on overall survival in patients with advanced non-small-cell lung cancer harbouring ALK gene rearrangement: a retrospective analysis. Lancet Oncol. 2011;12:1004-1012.

16. Charlson ME, Pompei P, Ales KL, MacKenzie CR. A new method of classifying prognostic comorbidity in longitudinal studies: development and validation. J Chron Dis. 1987;40:373383.

17. Zhou W, Heist RS, Liu G, et al. Smoking cessation before diagnosis and survival in early stage non-small cell lung cancer patients. Lung Cancer. 2006;53:375-380.

18. Nia PS, Weyler J, Colpaert C, Vermeulen P, Marck EV, Schil PV. Prognostic value of smoking status in operated non-small cell lung cancer. Lung Cancer. 2005;47:351-359.

19. Ebbert JO, Williams BA, Sun Z, et al. Duration of smoking abstinence as a predictor for non-small-cell lung cancer survival in women. Lung Cancer. 2005;47:165-172.

20. Bryant A, Cerfolio RJ. Differences in epidemiology, histology, and survival between cigarette smokers and never-smokers who develop non-small cell lung cancer. Chest. 2007;132:185-192.

21. Tammemagi CM, Neslund-Dudas C, Simoff M, Kvale P. Smoking and lung cancer survival: the role of comorbidity and treatment. Chest. 2004;125:27-37.

22. Gillum RF, Kwagyan J, Obisesan TO. Smoking, cognitive function and mortality in a US national cohort study. Int J Environ Res Public Health. 2011;8:3628-3636. 